\title{
COMUNIDADES MICROBIANAS, ATIVIDADE ENZIMÁTICA E FUNGOS MICORRÍZICOS EM SOLO RIZOSFÉRICO DE “LANDFARMING" DE RESÍDUOS PETROQUÍMICOS(1)
}

\author{
André Shigueyoshi Nakatani ${ }^{(2)}$, José Oswaldo Siqueira ${ }^{(3)}$, Cláudio \\ Roberto Fonsêca Sousa Soares ${ }^{(4)}$ \& Marcio Rodrigues Lambais ${ }^{(5)}$
}

\begin{abstract}
RESUMO
As raízes das plantas podem estimular a microbiota do solo, a qual pode contribuir para o aumento da eficiência do processo de remediação. Assim, avaliar a magnitude dos efeitos das raízes sobre a microbiota do solo é de grande interesse e de relevância prática e ecológica. Neste trabalho, avaliaram-se a densidade microbiana, a atividade enzimática, a estrutura da comunidade bacteriana e a presença de fungos micorrízicos arbusculares (FMAs) na rizosfera de plantas de ocorrência espontânea em solo de sistema de "landfarming" de resíduos petroquímicos. Avaliaram-se também solos rizosféricos de cinco plantas e solocontrole sem planta por meio de contagens de microrganismos em placas, eletroforese em gel com gradiente desnaturante (DGGE) de fragmentos do gene rRNA 16S, seqüenciamento genético, atividades enzimáticas, percentagem de colonização radicular e contagem e identificação de esporos de FMAs. As plantas estimularam a densidade microbiana total e da população de degradadores de antraceno, com contagens médias de $1,5 \times 10^{6}$ e $2,2 \times 10^{6}$ UFC g $^{-1}$ no solo seco, respectivamente, enquanto, no solo sem planta, essas contagens foram de 5,7 $\times 10^{5}$ e 2,9 $\times 10^{5} \mathrm{UFC}^{-1}$ no solo seco para os respectivos grupos microbianos. As espécies de maior efeito foram Bidens pilosa e Eclipta alba. Entretanto, esses efeitos estimulantes não foram verificados para a atividade enzimática do solo. A colonização micorrízica das raízes (em torno de 40 \%) e a densidade de esporos nos solos rizosféricos foram elevadas (entre 900 e 4.800 esporos por $50 \mathrm{~cm}^{3} \mathrm{de}$ solo), sendo maior na Brachiaria decumbens. Foram identificadas quatro espécies de FMAs: Acaulospora morrowiae, Glomus intraradices, Paraglomus occultum e Archaeospora trappei. Com exceção de G. intraradices, essas espécies não foram
\end{abstract}

\footnotetext{
(1) Parte da Dissertação de Mestrado do primeiro autor apresentada ao Programa de Pós-graduação em Microbiologia Agrícola, Universidade Federal de Lavras - UFLA. Desenvolvido com apoio financeiro do CNPq. Recebido para publicação em julho de 2007 e aprovado em abril de 2008.

${ }^{(2)}$ Doutorando em Microbiologia Agrícola da Escola Superior de Agricultura "Luiz de Queiroz" - ESALQ/USP. Av. Pádua Dias 11, Caixa Postal 9, CEP 13418-900 Piracicaba (SP). E-mail: nakatani@esalq.usp.br

${ }^{(3)}$ Docente do Departamento de Ciência do Solo, Universidade Federal de Lavras - UFLA. Campus Universitário, Caixa Postal 3037, CEP 37200-000 Lavras (MG). Bolsista CNPq. E-mail: siqueira@ufla.br

(4) Assistente de pesquisa PRODOC-CAPES do DCS-UFLA. Bolsista Prodoc-CAPES. E-mail: crfsoares@gmail.com

${ }^{(5)}$ Docente do Departamento de Ciência do Solo, ESALQ/USP. E-mail: mlambais@esalq.usp.br
} 
observadas em áreas contaminadas por hidrocarbonetos de petróleo. A análise por DGGE revelou que os solos rizosféricos apresentaram comunidades bacteriana diferente do solo sem plantas. As bactérias degradadoras de antraceno isoladas apresentaram relação filogenética com os gêneros Streptomyces, Nocardioides, Arthrobacter, Pseudoxanthomonas e com gêneros não identificados das famílias Cellulomonadaceae, Xanthomonadaceae e Rhodobacteraceae, sendo quatro destes isolados pertencentes aos actinomicetos. Apenas Nocardioides e o gênero relacionado com a família Cellulomonadaceae foram relatados em áreas brasileiras contaminadas com hidrocarbonetos de petróleo. Conclui-se que as plantas estimulam o aumento da densidade de células bacterianas e alteram a comunidade microbiana do solo de "landfarming" de resíduo petroquímico.

Termos de indexação: rizosfera, petróleo, microrganismos degradadores de antraceno, micorriza arbuscular, DGGE, rRNA 16S.

\section{SUMMARY: MICROBIAL COMMUNITIES, ENZYMATIC ACTIVITY AND MYCORRHIZAL FUNGI IN RHIZOSPHERIC SOIL USED FOR LANDFARMING OF PETROCHEMICAL WASTE}

The presence of plants stimulates soil microbiota, which may contribute to soil remediation. It is of great interest to quantify these effects on heterotrophic microorganisms due to their practical and ecological relevance. The following factors were evaluated: bacterial cell density, enzymatic activity, bacterial community structure and the spontaneous occurrence of arbuscular mycorrhizal fungi (AMF) in the plant rhizosphere in an area of land farming of petrochemical wastes, using a rhizospheric soil under five plants and control soil without plants. The following evaluation methods were applied: microorganism plate counts, molecular methods, denaturing gradient gel electrophoresis (DGGE) and gene sequencing, colorimetric methods for enzymes and percentage of root colonization, counting and identification of $A M F$ spores. Total and anthracene degrading microbial density were stimulated by the presence of plants, with average counts of $1.5 \times 10^{6}$ and $2.2 \times 10^{6} \mathrm{CFU} g$ dry soil-1, respectively, while soil without plants soil counts were $5.7 \times 10^{5}$ and $2.9 \times 10^{5} \mathrm{CFU} g$ dry soil ${ }^{-1}$ for the respective microbial groups. The species Bidens pilosa and Eleusine indica had the highest stimulatory effects on microbial density. No stimulating plant effects of soil enzymatic activity were verified. Root mycorrhizal colonization (around $40 \%$ ) and AMF spore density was high in rhizopheric soils (between 900 and 4,800 spores $50 \mathrm{~mL}$ soil $^{-1}$ ), especially in B. decumbens. Four AMF species were identified in this soil: Acaulospora morrowiae, Glomus intraradices, Paraglomus occultum and Archaeospora trappei. Aside from G. intraradices, this is the first report of the occurrence of these species in petroleum hydrocarbon contaminated areas. The DGGE analysis revealed existence of different bacterial communities in different treatments. The isolated anthracene degrading bacteria were related with the genera: Streptomyces, Nocardioides, Arthrobacter, Pseudoxanthomonas and non-identified genera of the families Cellulomonadaceae, Xanthomonadaceae and Rhodobacteraceae. Four of the identified genera belong to the actinomycetes. Only Nocardioides and the isolate related to the Cellulomonadaceae family have already been reported in areas contaminated with petroleum hydrocarbon in Brazil. In conclusion the presence of plants enhances soil bacterial cell density and alters the bacterial community in landfarming of petrochemical wastes.

Index terms: rhizosphere, petroleum, anthracene degrader microorganism, arbuscular mycorrhiza, DGGE, $16 S$ rRNA.

\section{INTRODUÇÃO}

O "landfarming" é uma técnica de biorremediação muito utilizada para o tratamento de resíduos da indústria petroquímica (Sims \& Sims, 1999). Essa técnica consiste na aplicação e incorporação do resíduo na camada arável do solo, para reduzir as concentrações dos constituintes de petróleo por meio de biodegradação microbiana. No entanto, ela não é eficiente para remover todos os contaminantes, especialmente os compostos mais recalcitrantes desses resíduos, os quais necessitam de técnicas complementares para a sua total remoção (Atagana, 2004). Muitos dos compostos recalcitrantes, como 
vários hidrocarbonetos aromáticos policíclicos (HAPs), são tóxicos, carcinogênicos e mutagênicos (Samanta et al., 2002).

Uma alternativa para aumentar a eficiência do "landfarming" é o emprego de plantas que possam estimular a degradação desses contaminantes, contribuindo para aumentar a eficiência do tratamento de HAPs, de pesticidas, de solventes clorados e de explosivos no solo (Susarla et al., 2002), degradando certas frações de hidrocarbonetos mais resistentes à biodegradação e de elevado risco à saúde humana e ambiental (Pradhan et al., 1998). O efeito estimulatório das raízes resulta, em parte, da modificação dos atributos físicos, químicos e biológicos do solo, estimulando as populações microbianas (Cunningham et al., 1996) a degradar contaminantes (Kirk et al., 2005). A contribuição das plantas para a eficiência do processo de remediação varia de acordo com as espécies e variedades vegetais (Siciliano et al., 2003), com as condições ambientais e propriedades do solo (Robson et al., 2003) e com as características físicoquímicas do contaminante (Binet et al., 2000a).

Embora não sejam empregadas plantas em áreas de "landfarming" em operação, é comum a ocorrência de algumas espécies em áreas (células) de biorremediação desativadas ou em solos retirados de células em atividade (Paula et al., 2006). Além de influenciar a comunidade microbiana do solo, a maioria das plantas forma associação simbiótica com alguns fungos Glomeromycota, denominado micorriza arbuscular. Há evidências de que os fungos simbiontes ocorrem em áreas de "landfarming" (Paula et al., 2006), podendo, entre outros, proteger as plantas contra os efeitos tóxicos desses poluentes (Binet et al., 2000b). Liu et al. (2004) observaram que plantas micorrizadas apresentam maior capacidade de estimular a degradação de hidrocarbonetos de petróleo no solo. Embora já empregado por várias indústrias, especialmente petroquímicas, no Brasil, há poucos estudos sobre "landfarming", sobretudo quando se considera a possibilidade de utilizar plantas para acelerar o processo de biorremediação.

O objetivo deste trabalho foi avaliar a densidade microbiana, a atividade enzimática, a estrutura da comunidade bacteriana e a presença de fungos micorrízicos arbusculares (FMAs) na rizosfera de diferentes espécies vegetais de crescimento espontâneo em solo de "landfarming" de resíduo petroquímico.

\section{MATERIAL E MÉTODOS}

\section{Caracterização do solo e amostragens}

Foram avaliadas amostras de solo de células de "landfarming" para tratamento de rejeitos da indústria petroquímica na empresa CETREL, em Camaçari (BA), em uso há mais de 15 anos. Em janeiro e fevereiro de 2004, as células receberam 153 t de borras oleosas de resíduos petroquímicos em uma área de $3.000 \mathrm{~m}^{2}$. Em abril de 2004, foram coletadas oito amostras simples do solo das células, a uma profundidade de 0-20 cm, para formar uma amostra composta. Elas foram utilizadas para os experimentos em casa de vegetação do Departamento de Ciência do Solo da Universidade Federal de Lavras (Lavras, MG). $\mathrm{O}$ solo pertence à classe textural arenosa (580, $310 \mathrm{e}$ $110 \mathrm{~g} \mathrm{~kg}^{-1}$ de areia, de silte e de argila, respectivamente). Seus atributos químicos são apresentados no quadro 1. Amostras de solo foram desagregadas e peneiradas em malha de $2 \mathrm{~mm}$ de diâmetro para uniformização e colocadas em vasos de $3 \mathrm{dm}^{3}$. Esses vasos foram empregados em estudos com Medicago sativa L. (alfafa), Pueraria phaseoloides (Roxb.) Benth. (kudzu tropical), Brachiaria brizantha (Hochst. ex A. Rich.) Stapf (braquiária), Styzolobium aterrimum Piper \& Tracy (mucuna-preta), Pennisetum purpureum Schumach. (capim-elefante) e Sorghum vulgare Pers. (sorgo), entre agosto e dezembro de 2004, para avaliações de medidas biológicas do solo (Paula et al., 2006).

Quadro 1. Características químicas do solo de célula de "landfarming" para tratamento de rejeitos da indústria petroquímica da empresa CETREL, em Camaçari, BA

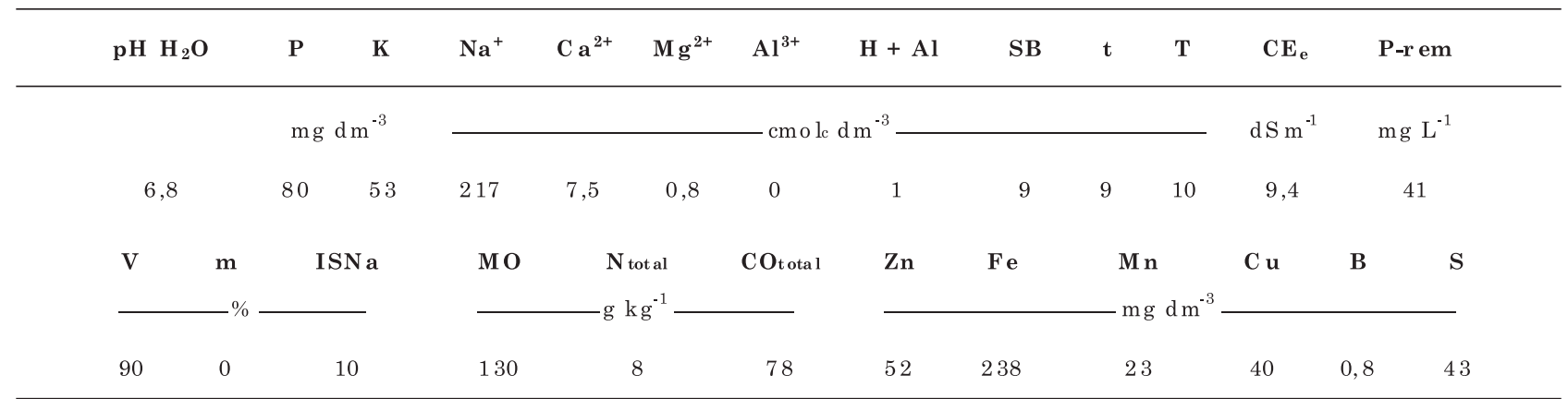

$\mathrm{H}+\mathrm{Al}$ : acidez potencial; $\mathrm{SB}$ : soma de bases trocáveis; t: CTC efetiva; T: $\mathrm{CTC}$ a $\mathrm{pH} 7,0$; $\mathrm{CE}_{\mathrm{e}}$ : condutividade elétrica a $25^{\circ} \mathrm{C}$; V: saturação por bases; m: saturação por Al da CTC efetiva; ISNa: índice de saturação por Na.

Fonte: Paula et al. (2006). 
Ao final desse experimento, todas as plantas foram removidas e o solo foi completamente homogeneizado e redistribuído nos vasos. Após umedecimento, surgiram plantas espontâneas, as quais cresceram no período de janeiro de 2005 a março de 2006, quando se procedeu à coleta de solo, solo rizosférico e raízes para avaliação. Para isso, plantas inteiras foram retiradas e agitadas levemente. O solo remanescente, aderido às raízes, foi considerado como solo rizosférico. As raízes foram colocadas em sacos plásticos e agitadas manualmente até a recuperação máxima do solo aderido ao sistema radicular. Foram coletadas amostras de quatro espécies de acordo com a ocorrência e freqüência nos vasos: Eleusine indica (L.) Gaertn. (capim pé-de-galinha), Bidens pilosa L. (picão-preto), Eclipta alba (L.) Hassk. (erva-de-botão), Cyperus sp. (tiririca) e Brachiaria decumbens Stapf (braquiária), sendo esta última introduzida por semeadura em dezembro de 2004. Como referência, coletaram-se amostras de solo não-rizosférico (solo de vaso com planta, porém fora da influência das raízes), e um de tratamento-controle, constituído do mesmo solo mantido em casa de vegetação por igual período, porém sem planta. As amostras de solo e de raízes foram coletadas de forma inteiramente casualizada, de modo a se obter sete tratamentos: solo rizosférico das cinco espécies e dois controles, com três repetições cada.

Também foram retiradas amostras compostas de solo para análises de teores de HAPs semivoláteis. Essas foram realizadas nos laboratórios da CETREL (Camaçari, BA), de acordo com o método EPA 8270D (USEPA, 2008), apresentando as seguintes concentrações em $\mathrm{mg} \mathrm{kg}^{-1}$ : naftaleno $0,06 \pm 0,04$; fluoreno $10,5 \pm 1,8$; antraceno $57,5 \pm 10,6$; fenantreno $2363,1 \pm 45,3 ; \quad$ fluoranteno $317,1 \pm 43,5$; benzo(a)antraceno $68,5 \pm 12,3$; benzo(a)pireno $38,9 \pm 5,1$; indeno(1,2,3-cd)pireno $119,1 \pm 11,1$; e dibenzo(a,h)antraceno 6,4 $\pm 0,9$.

\section{Avaliações microbiológicas}

A contagem de células viáveis de microrganismos foi feita em placa pelo método de diluições seriadas de suspensão de solo, utilizando os meios TSA para crescimento de bactérias totais, ágar extrato de malte para fungos totais, ágar Bushnell-Hass para bactérias degradadoras de hidrocarbonetos, e meio seletivo para fungos degradadores de hidrocarbonetos (Kirk et al., 2005). Para actinomicetos totais, utilizou-se ágar amido caseína, conforme Wellington \& Toth (1994). Nos meios de cultivo para o crescimento de microrganismos degradadores de hidrocarbonetos, foi utilizado, como única fonte de $\mathrm{C}$, o antraceno a $0,5 \%$, dissolvido em benzeno, modificado de Clemente et al. (2001), o qual foi uniformemente espalhado $(2,5 \mathrm{~mL}$ por placa) sobre a superfície do meio. O benzeno foi evaporado por $20 \mathrm{~min}$, formando uma fina camada de antraceno sobre a mesma superfície. Nos meios de cultivo para microrganismos heterotróficos totais, espalhou-se, superficialmente, o mesmo volume de benzeno, porém sem antraceno. As placas foram incubadas a $28^{\circ} \mathrm{C}$ em câmara escura, e as contagens de UFC foram efetuadas de 3 a 14 dias, de acordo com o microrganismo avaliado.

A atividade enzimática do solo foi avaliada pela determinação da hidrólise do diacetato de fluoresceína (DAF), de acordo com Schnürer \& Rosswall (1982), e da atividade da lipase, conforme Margesin et al. (2002).

A ocorrência de FMAs foi avaliada em amostras de $50 \mathrm{~cm}^{3}$ de solo, por meio da contagem de esporos em microscópico estereoscópico com aumento de até 40 vezes, após peneiramento úmido e centrifugação em solução de sacarose (Gerdemann \& Nicolson, 1963). As raízes das diferentes plantas de ocorrência espontânea foram coradas, segundo Phillips \& Haymann (1970), e avaliadas quanto à percentagem de colonização micorrízica, de acordo com Giovannetti $\&$ Mosse (1980). Os esporos foram contados, separados por morfotipos e preparados para identificação em lâminas com álcool polivinílico lactoglicerol e reagente de Melzer. A identificação taxonômica foi realizada pelo Dr. Sidney Stürmer (FURB, Blumenau, SC).

\section{Análise da estrutura da comunidade bacteriana do solo}

A estrutura da comunidade bacteriana do solo rizosférico foi avaliada por meio da separação de fragmentos do gene codificando o rRNA 16S, amplificado por meio da reação em cadeia da polimerase (PCR) por eletroforese em gel com gradiente desnaturante (DGGE) (Muyzer et al., 1993). Para cada tratamento, as três repetições das amostras de solo foram misturadas para formar uma amostra composta.

O DNA metagenômico de cada tratamento foi extraído a partir de 0,5 g de solo, utilizando-se o Fast DNA SPIN KIT para solo (Q-Biogene, EUA), de acordo com as instruções do fabricante. A região V3 do gene codificando o rRNA 16S foi amplificada por PCR, utilizando-se o DNA metagenômico extraído e os oligonucleotídeos iniciadores (5' GCC CGC CGC GCG CGG CGG GCG GGG CGG GGG CAC GGA CTC CTA CGG GAG GCA GCA G 3') e UN518r (5' ATT ACC GCG GCT GCT GG 3') (Øvreås et al., 1997). A reação foi realizada em um volume de $25 \mu \mathrm{L}$ com $1 \mathrm{X}$ Taq Platinum DNA polymerase buffer, $0,1 \mathrm{mmol} \mathrm{L}^{-1}$ dNTPs, $1,5 \mathrm{mmol} \mathrm{L}^{-1} \mathrm{MgCl}_{2}$, 0,625 U Taq Platinum DNA polimerase (Invitrogen, Brasil), 1 pmol dos primers e 10 ng do DNA metagenômico. As condições de amplificação foram de 5 min a $95^{\circ} \mathrm{C}$; 30 ciclos de $1 \min$ a $92{ }^{\circ} \mathrm{C}$; $1 \min$ a $55{ }^{\circ} \mathrm{C}$; e de 1 min a $72{ }^{\circ} \mathrm{C}$. A extensão final foi de $10 \mathrm{~min}$ a $72^{\circ} \mathrm{C}$.

Quantidades iguais de amplicons (300 ng) foram analisadas por meio de géis com $8 \%$ de acrilamida: bisacrilamida (37,5:1, m:m), que continham um gradiente desnaturante de 15 a $55 \%$, preparado com mistura de solução desnaturante $\left(7 \mathrm{~mol} \mathrm{~L}^{-1}\right.$ uréia e $40 \mathrm{cL} \mathrm{L}^{-1}$ de formamida) e solução a $0 \%$ (sem uréia e formamida) (Øvreås et al., 1997). A eletroforese foi realizada a $200 \mathrm{~V}$ constantes e $60^{\circ} \mathrm{C}$ por $4 \mathrm{~h}$, utilizan- 
do-se o sistema "DCode" (BioRad, EUA), em tampão 0,5X TAE. O DNA foi corado com "SYBR Green" (GE Healthcare, Brasil). Os géis foram analisados por densitometria usando um densitômetro laser "FluorImager" (GE Healthcare, Brasil) e o programa "Diversity Database" (BioRad, EUA). Os perfis de bandas após DGGE foram analisados por agrupamento hierárquico utilizando-se o programa SYSTAT 11.0, com base em dados binários, pelo método de concordância simples ("simple matching"), com algoritmo de Ward e distância euclidiana como unidade de medida.

\section{Seqüenciamento do gene rRNA $16 \mathrm{~S}$ de bactérias degradadoras de antraceno}

Colônias de bactérias degradadoras de antraceno foram obtidas a partir do plaqueamento de diluições seriadas da mistura de solos rizosféricos de Bidens pilosa, Cyperus sp. e Eclipta alba, as quais apresentaram maiores contagens de UFC de bactérias capazes de utilizar antraceno como única fonte de $\mathrm{C}$ em placa.

Dez isolados bacterianos foram purificados em meio ágar Bushnell-Hass com antraceno a $5 \mathrm{~g} \mathrm{~L}^{-1}$. As células de colônias bacterianas foram suspensas em $50 \mu \mathrm{L}$ de água ultrapura e lisadas a $95^{\circ} \mathrm{C}$, por $5 \mathrm{~min}$. Para o PCR foi utilizado $1 \mu \mathrm{L}$ do lisado celular nas mesmas condições supradescritas, exceto para os oligonucleotídeos iniciadores $1541 \mathrm{R}$ (5'AAGGAGGTGATCCAGCCGCA3') e 8F (5'AGAGTTTGATCCTGGCTCAG3') (Löffler et al., 2000). O DNA foi precipitado com etanol a $98 \mathrm{cL} \mathrm{L}^{-1}$, que continha acetato de amônio $\left(7,5 \mathrm{~mol} \mathrm{~L}^{-1}\right)$, e o pelete foi lavado com etanol a $70 \mathrm{cL} \mathrm{L}^{-1}$. Para o seqüenciamento dos produtos da PCR, foram utilizados 200-500 ng do DNA purificado, 5 pmol do oligonucleotídeo iniciador $\quad 63 \mathrm{~F}$ (5'CAGGCCTAACACATGCAAGTC3) (Marchesi et al., 1998), $1 \mu \mathrm{L}$ de "DYEmanic ET Terminator" (Amersham Biosciences, Brasil), $3 \mu \mathrm{L}$ de tampão de seqüenciamento $\left(200 \mathrm{mmol} \mathrm{L}^{-1}\right.$ Tris- $\mathrm{HCl} \mathrm{pH} 9,0 \mathrm{e}$ $5 \mathrm{mmol} \mathrm{L}-1 \mathrm{MgCl}_{2} \cdot 6 \mathrm{H}_{2} \mathrm{O}$ ) e água ultrapura para um volume final de $10 \mu \mathrm{L}$, em 25 ciclos de $20 \mathrm{~s}$ a $95^{\circ} \mathrm{C}$, de $15 \mathrm{~s} \mathrm{a} 54^{\circ} \mathrm{C}$ e de 1 min a $60^{\circ} \mathrm{C}$. Os produtos da PCR de seqüenciamento foram precipitados em etanol a $98 \mathrm{cL} \mathrm{L}^{-1}$, que continha acetato de sódio $\left(3 \mathrm{~mol} \mathrm{~L}^{-1}\right) /$ EDTA $\left(0,5 \mathrm{~mol} \mathrm{~L}^{-1}\right)$, e lavado em etanol a $70 \mathrm{cL} \mathrm{L}^{-1}$. A eletroforese foi feita em um seqüenciador automático ABI 3100, de acordo com as instruções do fabricante (Applied Biosystems, Brasil). Foi seqüenciado o DNA proveniente de três colônias de cada isolado bacteriano. As seqüências foram processadas no programa PHRED para a remoção de bases com baixa qualidade (critério de qualidade $>20$, menos de um erro em 100 nucleotídeos). Para a afiliação filogenética das seqüências, utilizou-se o programa RDPquery (http:// rdp.cme.msu.edu/ - Release 9.51). As seqüências foram depositadas no GenBank sob o número de acesso EU541521 - EU541539. A árvore filogenética foi construída por meio do método de neighbor joining, usando o programa MEGA 3.1.
As contagens das UFC foram transformadas em $\log _{10}$. Os dados de contagem, a atividade enzimática e os FMAs foram analisados pelo cálculo do erro-padrão das médias e por meio do teste t de Student para correlação linear de Pearson.

\section{RESULTADOS E DISCUSSÃO}

\section{Densidade e atividade microbiana}

Verificou-se que as plantas favoreceram a microbiota heterotrófica total e degradadora de antraceno em relação ao solo não-rizosférico e sem planta (Figura 1). Em geral, todos os grupos microbianos avaliados apresentaram maiores populações nos solos rizosféricos: o número de UFC de bactérias totais nos solos rizosféricos foi maior, em média, 5,2 vezes; o de bactérias degradadoras de antraceno, 8,7 vezes maior; o de fungos totais, 3,0 vezes maior; os fungos degradadores de antraceno, 2,8 vezes maior, e o de actinomicetos, $1,3 \mathrm{vez}$ superior ao valor obtido em vasos sem plantas.

Dentre as plantas, destacam-se Bidens pilosa e Eclipta alba, que apresentaram maiores contagens de UFC de microrganismos totais e degradadores de antraceno. Em solos com essas plantas, o número de UFC de bactérias degradadoras de antraceno foi de $7,5 \times 10^{6}$ e $5,6 \times 10^{6}$ UFC g-1 $^{-1}$ no solo seco, respectivamente, enquanto o solo sem planta apresentou $4,9 \times 10^{5} \mathrm{UFC} \mathrm{g}^{-1}$ no solo seco.

Maior densidade microbiana na rizosfera em solos contaminados com hidrocarbonetos de petróleo tem sido relatada em diversos trabalhos (Muratova et al., 2003a,b). A introdução de alfafa e caniço (Phragmites australis (Cav.) Trin. ex Steud) em solo contaminado com HAPs pode estimular o aumento das populações da maioria dos grupos microbianos avaliados e da população de microrganismos degradadores de hidrocarbonetos, sendo o efeito mais pronunciado no tratamento com alfafa (Muratova et al., 2003a). Aumentos de até 11 vezes no número de UFC de bactérias totais na rizosfera de mostarda foram observados em solo contaminado com hidrocarbonetos de petróleo (Liste \& Felgentreu, 2006).

Os valores relativamente elevados do número de UFC de actinomicetos em todos os solos (média geral de $7,3 \times 10^{5} \mathrm{UFC} \mathrm{g}^{-1}$ no solo seco) foram semelhantes aos encontrados em solos de cerrado não contaminados (Pereira et al., 1999). No entanto, esses valores foram menores que os observados em solos contaminados com óleo diesel na Finlândia (Palmroth et al., 2005), nos quais Pinus sylvestris L. e Populus deltoides Marshall não alteraram significativamente a população de actinomicetos. Neste estudo, a contagem de UFC de actinomicetos apresentou relação positiva com a contaminação do solo $\left(\hat{y}=5,6+0,06 x ; R^{2}=0,533\right.$, 

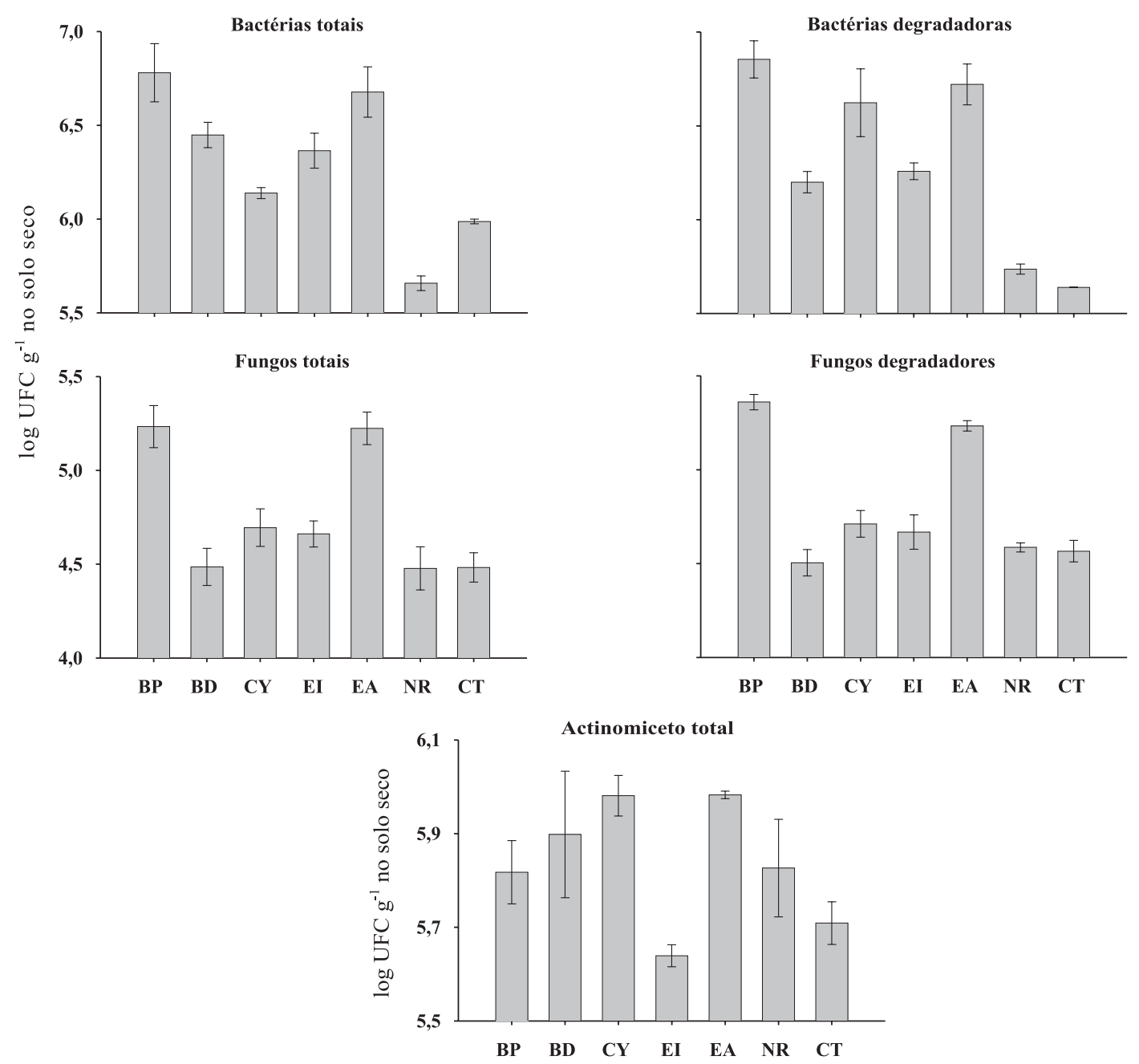

Figura 1. Contagem de células viáveis de microrganismos totais e degradadores de antraceno em solos rizosféricos de plantas de crescimento espontâneo em área de "landfarming" de resíduos petroquímicos. BP (Bidens pilosa), BD (Brachiaria decumbens), CY (Cyperus sp.), EI (Eleusine indica), EA (Eclipta alba), NR (Solo não-rizosférico) e CT (Solo- controle sem planta). Linhas verticais indicam o erropadrão da média $(n=3)$.

$\mathrm{p}<0,05)$, sugerindo algum estímulo dos hidrocarbonetos sobre esse grupo de microrganismos. A alta densidade de actinomicetos, inclusive nos solos sem planta, indica a sua ampla ocorrência em solos contaminados com hidrocarbonetos de petróleo, em que apresentam vasta diversidade catabólica e tolerância a condições estressantes (Pizzul et al., 2006). De fato, Johnsen et al. (2002) relataram que, em alguns locais contaminados com HAPs, os actinomicetos representam o grupo dominante entre os degradadores de fenantreno.

A qualidade e a quantidade de exsudados radiculares, bem como a morfologia radicular, variam entre as espécies vegetais, e isso tem grande influência sobre as propriedades microbiológicas da rizosfera (Binet et al., 2000b; Landi et al., 2006), as quais podem afetar a taxa de degradação dos compostos contaminantes no solo. Portanto, a ocorrência de plantas em solos de áreas contaminadas pode contribuir para a eficiência da descontaminação (Merkl et al., 2004). Muratova et al. (2003a) observaram que na rizosfera de alfafa, a densidade microbiana e a degradação de HAPs no solo são maiores do que na rizosfera de caniço, mostrando que a espécie vegetal pode ter efeito direto na taxa de degradação de HAPs no solo.

A atividade biológica do solo, avaliada por meio da hidrólise do DAF, foi pouco influenciada pelas plantas, embora algum destaque possa ser atribuído ao solo com Eleusine indica, com maior valor em relação ao solo-controle (Figura 2). A atividade do DAF nesse solo contaminado com hidrocarbonetos de petróleo foi, em média, 35,7 $\mu \mathrm{g} \mathrm{g}^{-1} \mathrm{~h}^{-1}$ de $\mathrm{F}$ no solo, situando-se entre os valores geralmente relatados na literatura para essa situação (Margesin et al., 2003a; Andreoni et al., 2004). Como o DAF é hidrolisado por várias enzimas (proteases, lipases e esterases), os valores de atividade são influenciados por inúmeros fatores, como 

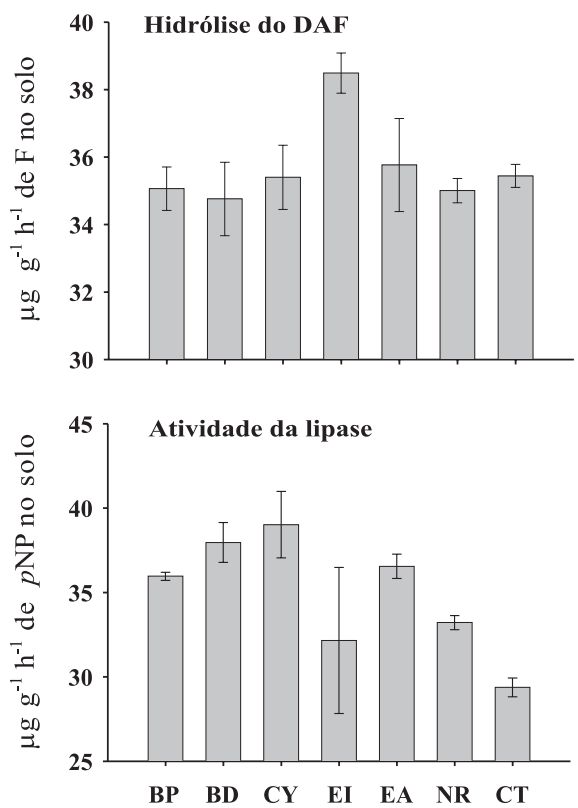

Figura 2. Atividade enzimática (hidrólise do diacetato de fluoresceína - DAF e atividade da lipase) em solos rizosféricos de plantas de crescimento espontâneo em área de "landfarming" de resíduos petroquímicos, sendo pNP para-nitrofenol e $\mathrm{F}$ fluoresceína. BP (Bidens pilosa), BD (Brachiaria decumbens), $\mathrm{CY}$ (Cyperus sp.), EI (Eleusine indica), EA (Eclipta alba), NR (Solo não-rizosférico) e CT (Solocontrole sem planta). Linhas verticais indicam o erro-padrão da média $(n=3)$.

a composição do contaminante, o tempo de contaminação e a presença de compostos inibidores dessas enzimas, resultando em atividades muito variáveis (Margesin et al., 2003b).

Houve maior atividade da lipase no solo com Bidens pilosa, com Brachiaria decumbens, com Cyperus sp e com Eclipta alba (média de $37,4 \mu \mathrm{g} \mathrm{g}^{-1} \mathrm{~h}^{-1} \mathrm{de}$ $p \mathrm{NP}$ no solo). Já com Eleusine indica, a atividade da lipase não diferiu daquela observada no solo-controle sem planta (Figura 2). A atividade média dessa enzima ficou abaixo dos valores observados em solos contaminados com óleo diesel por Riffaldi et al. (2006) (199 a $535 \mu \mathrm{g} \mathrm{g}^{-1} \mathrm{~h}^{-1}$ de $p \mathrm{NP}$ no solo), porém na faixa de valores relatados por Margesin \& Schinner (2001). De acordo com Margesin et al. (2002), solos com histórico recente de contaminação apresentam elevada atividade da lipase, comportamento este não observado neste estudo, em que os solos amostrados recebem HAPs há mais de 15 anos.

É possível que o tipo de solo arenoso deste estudo e o acúmulo de metais pesados dos resíduos petroquímicos, que inibe a atividade da lipase (Margesin et al., 2002), expliquem os baixos valores dessa enzima encontrados neste trabalho. Verificouse relação positiva significativa entre a atividade da lipase e o número de UFC de bactérias degradadoras de antraceno e de actinomicetos totais (Figura 3a), corroborando com os resultados de Margesin et al. (1999), em solo contaminado com óleo diesel. Ko et al. (2005) observaram que cerca de $25 \%$ das bactérias totais e $65 \%$ dos actinomicetos isolados do solo são produtores de lipases. Neste trabalho, observou-se também relação positiva significativa entre a concentração de HAPs e a atividade da lipase (Figura 3b), a qual se pode tornar ferramenta útil para monitorar a biodegradação de óleos no solo. Isso pelo fato de sua atividade não ser reduzida à medida que $o$ tempo de contaminação aumenta ou a taxa de biodegradação diminui (Margesin et al., 1999).

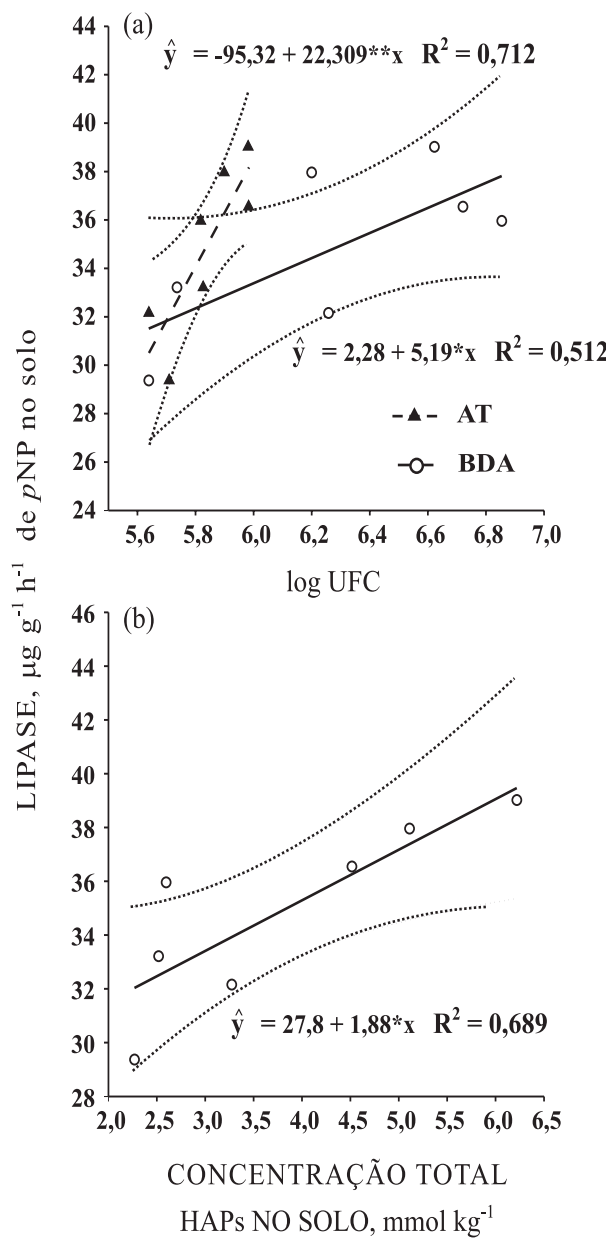

Figura 3. Equações de regressão entre a atividade da lipase e a contagem de bactérias degradadoras e actinomicetos totais (a), e entre a concentração molar total de hidrocarbonetos semivoláteis extraíveis e a atividade da lipase (b) em solos de área de "landfarming" de resíduos petroquímicos. BDA (Bactéria degradadora de antraceno), AT (Actinomiceto total). Linhas pontilhadas representam o intervalo de confiança da amostragem a $95 \%$ de probabilidade. **** regressão significativa pelo teste $t$ de Student a 5 e $1 \%$, respectivamente. 
A colonização micorrízica das raízes variou de 14 a $56 \%$, em Cyperus sp. e Brachiaria decumbens, respectivamente (Figura 4), enquanto a densidade de esporos de FMAs no solo variou de 895 a 4738 esporos por $50 \mathrm{~cm}^{3}$ de solo para Eleusine indica e Brachiaria decumbens, respectivamente. No solo-controle, a densidade de esporos foi de 65 esporos por $50 \mathrm{~cm}^{3} \mathrm{de}$ solo (Figura 4). Foram identificadas quatro espécies de FMAs nas amostras: Acaulospora morrowiae, Glomus intraradices, Paraglomus occultum e Archaeospora trappei em todos os tratamentos, apresentando $A$. morrowiae maior número de esporos. As taxas de colonização micorrízica encontradas são semelhantes às observadas por Cabello (1997) em plantas de ocorrência natural em dois solos contaminados com compostos orgânicos derivados de petróleo na Argentina e na Alemanha. Paula et al. (2006), trabalhando com o mesmo solo deste estudo, observaram que, apesar da baixa densidade de esporos de FMAs (Glomus sp.), a colonização espontânea das raízes de plantas introduzidas foi elevada (30 a 62 \%).
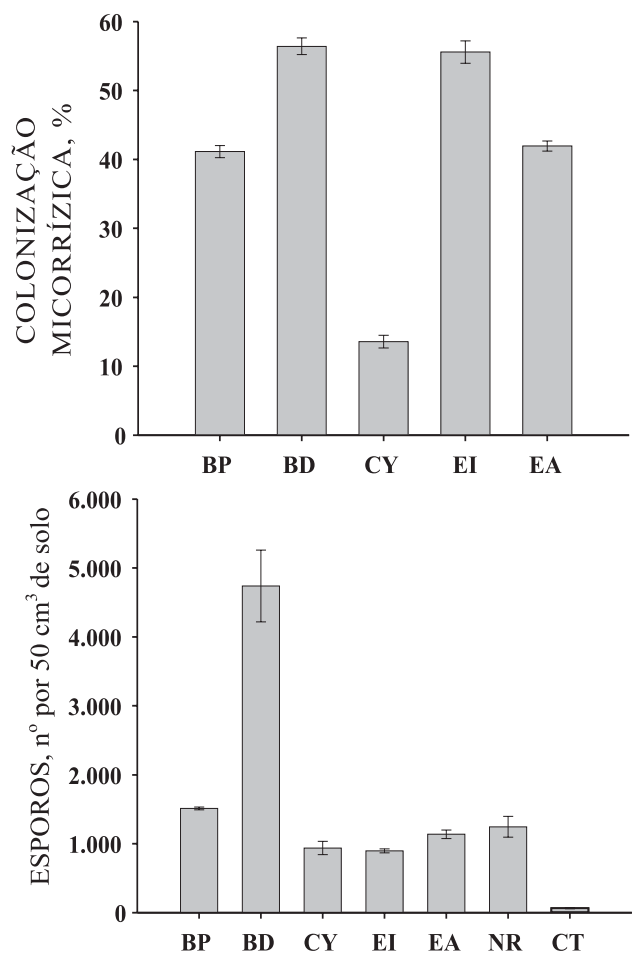

Figura 4. Colonização e densidade de esporos de fungos micorrízicos arbusculares em solos rizosféricos de plantas de crescimento espontâneo de área de "landfarming" de resíduos petroquímicos. $\mathrm{BP}$ (Bidens pilosa), $\mathrm{BD}$ (Brachiaria decumbens), CY (Cyperus sp.), EI (Eleusine indica), EA (Eclipta alba), NR (Solo não-rizosférico) e CT (Solo-controle sem planta). Linhas verticais indicam o erro-padrão da média $(n=4$ repetições para colonização e $n=3$ para esporos).
O constante revolvimento do solo em sistema de "landfarming" dificulta o estabelecimento de vegetação e, assim, a formação de micorrizas. No entanto, plantas que cresceram em solos retirados das células biorremediadoras foram capazes de formar micorrizas arbusculares e os FMA nativos esporularam intensamente.

Os FMAs são biotróficos obrigatórios e os mecanismos que regulam sua esporulação são ainda desconhecidos. Há evidências de que certos compostos orgânicos, como pesticidas e metabólitos vegetais, podem estimular a esporulação (Trappe et al., 1984, Davies Jr. et al., 2005). Diversas espécies de FMAs têm sido encontradas em solos contaminados com HAPs, tais como: Glomus deserticola, G. mosseae, $G$. agregatum, Gigaspora sp. (Cabello, 1997), G. fasciculatum, G. microcarpum, Entrophospora infrequens (Stahl \& Williams, 1986), G. geosporum, G. intraradices (Cabello, 1999) e Glomus sp. (Paula et al., 2006). Com exceção de $G$. intraradices, este é o primeiro relato da ocorrência de $A$. morrowiae, $P$. occultum e $A$. trappei em áreas contaminadas com HAPs.

\section{Estrutura da comunidade bacteriana e seqüenciamento do gene rRNA $16 \mathrm{~S}$}

A estrutura da comunidade bacteriana do solo, avaliada por DGGE, foi influenciada pela presença de plantas (Figura 5). A análise de agrupamento hierárquico, de acordo com a presença ou da ausência de bandas com diferentes mobilidades no gel de poliacrilamida, revelou que os padrões de bandas podem ser divididos em dois grupos: o primeiro, que inclui os solos não-rizosféricos e sem planta; e o segundo, que engloba todos os solos com plantas (Figura 5). Este último ainda pode ser dividido em dois subgrupos: um, que engloba as quatro plantas de crescimento espontâneo; e o outro, da Brachiaria decumbens, que foi introduzida por semeadura. Esses dados indicam que as espécies de ocorrência natural nesses solos apresentam estruturas de comunidade bacteriana diferentes daquelas associadas à espécie introduzida.

Os padrões de distribuição das bandas entre os tratamentos foram diferentes, mostrando que a rizosfera apresenta estrutura distinta das populações bacterianas do solo sem planta. A aplicação continuada por 15 anos de resíduos petroquímicos ao solo pode ter alterado a composição da microbiota, selecionando populações mais adaptadas a essa situação estressante. Considerando que a intensidade das bandas reflete a abundância das populações, podese inferir que algumas populações bacterianas são mais abundantes nos solos com plantas em comparação ao solo-controle sem essas. A dominância de algumas espécies bacterianas pode ser favorecida na rizosfera, enquanto a contaminação favorece outras espécies. Isto pode explicar a ocorrência de espécies dominantes na rizosfera de plantas em áreas contaminadas (Kim et al., 2006). 
A identificação das bactérias de solo contaminado, isoladas em meio com antraceno, e a árvore filogenética gerada a partir das seqüências obtidas, são apresentadas na figura 6 . Os isolados de bactérias degradadoras de antraceno classificados pelo RDPquery foram relacionados com os gêneros Streptomyces, Nocardioides, Arthrobacter, Pseudoxanthomonas e gênero não identificado das

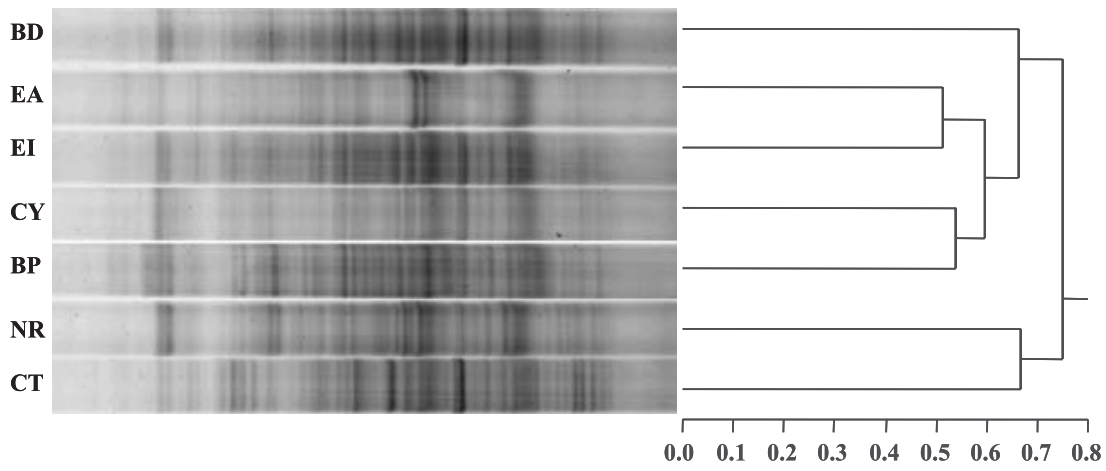

Figura 5. Estrutura das comunidades de bactérias com base nos perfis de fragmentos do rRNA 16S de solo rizosférico de plantas de crescimento espontâneo em sistema de "landfarming" de resíduos petroquímicos após DGGE. BP (Bidens pilosa), BD (Brachiaria decumbens), CY (Cyperus sp.), EI (Eleusine indica), EA (Eclipta alba), NR (Solo não-rizosférico) e CT (Solo-controle sem planta).

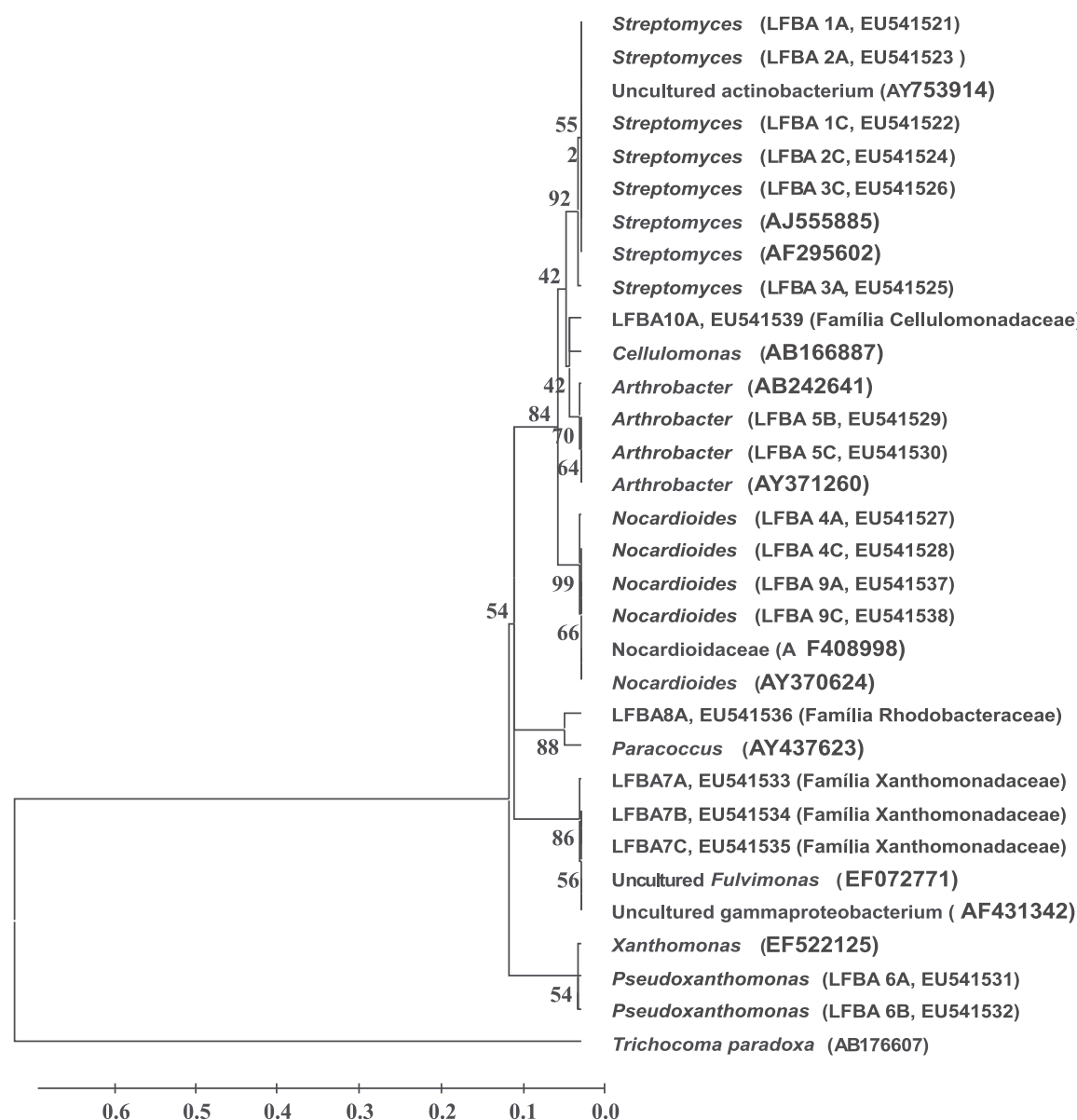

Figura 6. Árvore filogenética de isolados bacterianos degradadores de antraceno na rizosfera de plantas de crescimento espontâneo em solo de "landfarming" de resíduo petroquímico e isolados recuperados do GenBank. A pesquisa foi baseada na análise neighbor joining, construída com base de 1.000 réplicas de "bootstrap". Os valores mostrados na árvore são dados em percentagem de "bootstrap". O taxon é seguido pela sigla do isolado e, ou, de número de acesso no GenBank. 
famílias Cellulomonadaceae, Xanthomonadaceae e Rhodobacteraceae. Microrganismos que utilizam hidrocarbonetos como fonte de $\mathrm{C}$ ou que apresentam tolerância aos contaminantes, têm sido identificados em locais com diferentes históricos de contaminação com hidrocarbonetos de petróleo e em diversos tipos de solos (Juck et al., 2000; Chaerun et al., 2004; Brito et al., 2006). Jussila et al. (2006) identificaram 50 bactérias de 11 gêneros na rizosfera de Galega orientalis Lam., contaminada com óleo cru, e verificaram que $20 \%$ delas foram capazes de degradar $m$-tolueno.

Dos isolados seqüenciados neste estudo, quatro pertencem à ordem Actinomycetales: Streptomyces, Nocardioides, Arthrobacter e uma espécie não identificada da família Cellulomonadaceae. Juck et al. (2000) observaram que, em solo contaminado com óleo diesel, $64 \%$ das bactérias pertenciam à ordem Actinomycetales. A capacidade desse grupo de microrganismo degradar hidrocarbonetos de petróleo tem sido reportada na literatura (Chaerun et al., 2004; Brito et al., 2006; Jussila et al., 2006), indicando que ele dispõe de mecanismos de adaptação a essas condições e que pode ser valioso para o desenvolvimento de novas estratégias de biorremediação (Brito et al., 2006).

No Brasil, ainda são poucos os trabalhos com esse objetivo. Dentre os gêneros de bactérias degradadoras de antraceno identificados neste estudo, apenas Nocardioides e Cellulomonas (família Cellulomonadaceae) já foram relatados em solos brasileiros contaminados com hidrocarbonetos de petróleo (Sá, 2002; Brito et al., 2006).

\section{CONCLUSÕES}

1. As plantas de crescimento espontâneo em solo de "landfarming" favoreceram a densidade microbiana do solo, porém esses efeitos foram diferenciados para grupos microbianos e espécie vegetal. Enquanto bactérias e fungos totais e degradadores de antraceno foram mais favorecidos por Bidens pilosa e Eclipta alba, o estímulo das plantas sobre os actinomicetos totais foi menos acentuado.

2. Apesar dos baixos valores de atividade da lipase, os solos rizosféricos apresentaram maiores atividades dessa enzima em relação ao solo sem plantas.

3. A colonização micorrízica foi elevada, enquanto a densidade de esporos foi diferente entre as espécies vegetais, destacando-se a Brachiaria decumbens, que revelou elevada densidade. Foram encontradas quatro espécies de fungos micorrízicos: Glomus intraradices, Acaulospora morrowiae, Paraglomus occultum e Archaeospora trappei. Destas, somente a primeira espécie já havia sido relatada em solos contaminados com HAPs.
4. Houve influência das plantas na estrutura da comunidade bacteriana do solo, sendo encontradas populações microbianas distintas na rizosfera em relação ao solo sem planta.

5. Dentre as bactérias identificadas, degradadoras de antraceno da rizosfera (Streptomyces, Nocardioides, Arthrobacter, Pseudoxanthomonas), e espécies não identificadas das famílias Cellulomonadaceae, Xanthomonadaceae e Rhodobacteraceae, quatro pertenciam à ordem Actinomycetales e cinco foram encontradas pela primeira vez em solos contaminados com HAPs no Brasil.

\section{LITERATURA CITADA}

ANDREONI, V.; CAVALCA, L.; RAO, M.A.; NOCERINO, G.; BERNASCORRI, S.; COLOMBO, M. \& GIANFREDA, L. Bacterial communities and enzymes activities of PAH polluted soils. Chemosphere, 57:401-412, 2004.

ATAGANA, H.I. Bioremediation of creosote-contaminated soil in South Africa by landfarming. J. Appl. Microbiol., 96:510$520,2004$.

BINET, P.H.; PORTAL, J.M. \& LEYVAL, C. Fate of polycyclic aromatic hydrocarbons (PAH) in the rhizosphere and mycorrhizosphere of ryegrass. Plant Soil, 227:207-213, 2000a.

BINET, P.H.; PORTAL, J.M. \& LEYVAL, C. Dissipation of 3-6ring polycyclic aromatic hydrocarbons in the rhizosphere of ryegrass. Soil Biol. Biochem., 32:2011-2017, $2000 \mathrm{~b}$.

BRITO, E.M.S.; GUYONEAUD, R.; GÕNI-URRIZA, M.; RANCHOU-PEYRUSE, A.; VERBAERE, A.; CRAPEZ, M.A.C.; WASSERMAN, J.C.A. \& DURAN, R. Characterization of hydrocarbonoclastic bacterial communities from mangrove sediments in Guanabara Bay, Brazil. Res. Microbiol., 157:752-762, 2006.

CABELLO, M.N. Effectiveness of indigenous arbuscular mycorrhizal fungi (AMF) isolated from hydrocarbon polluted soils. J. Basic Microbiol., 39:89-95, 1999.

CABELLO, M.N. Hydrocarbon pollution: its effects on native arbuscular mycorrhizal fungi (AMF). FEMS Microbiol. Ecol., 22:233-236, 1997.

CHAERUN, S.K.; TAZAKI, K.; ASADA, R. \& KOGURE, K. Bioremediation of coastal areas 5 years after the Nakhodka oil spill in the Sea of Japan: Isolation and characterization of hydrocarbon-degrading bacteria. Environ. Intern., 30:911-922, 2004.

Clemente, A.R.; ANAZAWA, T.A. \& DURRANT, L.R. Biodegradation of polycyclic aromatic hydrocarbons by soil fungi. Braz. J. Microbiol., 32:255-261, 2001.

CUNNINGHAM, S.D.; ANDERSON, T.A. \& SHWAB, A.P. Phytoremediation of soils contaminated with organic pollutants. Adv. Agron., 56:55-114, 1996.

DAVIES JR, F.T.; CALDERÓN, C.M.; HUAMAN, Z. \& GÓMEZ, R. Influence of a flavonoid (formononetin) on mycorrhizal activity and potato crop productivity in the highlands of Peru. Sci. Hortic., 106:318-329, 2005. 
GERDEMANN, J.B. \& NICOLSON, T.H. Spores of mycorrhizal endogone species extracted from soil by wet sieving and decanting. Trans. British Mycol. Soc., 46:235-246, 1963.

GIOVANNETTI, M. \& MOSSE, B. An evaluation of techniques for measuring vesicular arbuscular mycorrhizal infection in roots. New Phytol., 84:489-500, 1980.

JOHNSEN, A.R.; WINDING, A.; KARLSON, U. \& ROSLEV, P. Linking of microorganisms to phenathrene metabolism in soil by analysis of 13C-labeled cell lipids. Appl. Environ. Microbiol., 68:6106-6113, 2002

JUCK, D.; CHARLES, T.; WHYTE, L.G. \& GREER, C.W Polyphasic microbial community analysis of petroleum hydrocarbon-contaminated soils from two northern Canadian communities. FEMS Microbiol. Ecol., 33:241249,2000

JUssilA, M.M.; JURGENS, G.; LINDSTRÖM, K. \& SUOMINEN, L. Genetic diversity of culturable bacteria in oil-contaminated rhizosphere of Galega orientalis. Environ. Pollut., 139:244-257, 2006.

KIM, J.; KANG, S.H.; MIN, K.A.; CHO, K.S. \& LEE, I.S. Rhizosphere microbial activity during phytoremediation of diesel-contaminated soil. J. Environ. Sci. Health Part A-Toxic/Hazard. Subst. Environ. Eng., 41:2503-2516, 2006.

KIRK, J.L.; KLIRONOMOS, J.N.; LEE, H. \& TREVORS, J.T. The effects of perennial ryegrass and alfalfa on microbial abundance and diversity in petroleum contaminated soil. Environ. Pollut., 133:455-465, 2005.

KO, W.H.; WANG, I.T. \& ANN, P.J. A simple method for detection of lipolytic microorganisms in soils. Soil Biol. Biochem., 37:597-599, 2005.

LANDI, L.; VALORI, F.; ASCHER, J.; RENELLA, G.; FALCHINI, L. \& NANNIPIERI, P. Root exudate effects on the bacterial communities, $\mathrm{CO}_{2}$ evolution, nitrogen transformations and ATP content of rhizosphere and bulk soils. Soil Biol. Biochem., 38:509-516, 2006.

LISTE, H.H. \& FELGENTREU, D. Crop growth, culturable bacteria, and degradation of petrol hydrocarbons (PHCs) in a long-term contaminated field soil. Appl. Soil Ecol., $31: 43-52,2006$

LIU, S.L.; LUO, Y.M.; CAO, Z.H.; WU, L.H.; DING, K.Q. \& CHRISTIE, P. Degradation of benzo(a)pyrene in soil with arbuscular mycorrhizal alfalfa. Environ. Geochem. Health, 26:285-293, 2004

LÖFFLER, F.E.; SUN, Q.; LI, J. \& TIEDJE, J.M. 16S rRNA Gene-based detection of tetrachloroethenedechlorinating Desulforomonas and Dehalococcoides species. Appl. Environ. Microbiol., 66:1369-1374, 2000.

MARCHESI, J.R.; SATO, T.; WEIGHTMAN, A.J.; MARTIN, T.A.; FRY, J.C.; HIOM, S.J. \& WADE, W.G. Design and evaluation of useful bacterium-specific PCR primers that amplify genes coding for bacterial 16S rRNA. Appl. Environ. Microbiol., 64:795-799, 1998.

MARGESIN, R. \& SCHINNER, F. Bioremediation (natural attenuation and biostimulation) of diesel-oil-contaminated soil in an Alpine glacier skiing area. Appl. Environ. Microbiol., 67:3127-3133, 2001.
MARGESIN, R.; FELLER, G.; HÄMMERLE, M.; STEGNER, U. \& SCHINNER, F. A colorimetric method for the determination of lipase activity in soil. Biotechnol. Lett., 24: 27-33, 2002 .

MARGESIN, R.; LABBÉ, D.; SCHINNER, F.; GREER, C.W. \& WHYTE, L.G. Characterization of hydrocarbon-degrading microbial populations in contaminated and pristine alpine soils. Appl. Environ. Microbiol., 69:3085-3092, 2003a.

MARGESIN, R.; GANDER, S.; ZACKE, G.; GOUNOT, A.M. \& SCHINNER, F. Hydrocarbon degradation and enzyme activities of cold-adapted bacteria and yeasts. Extremophiles, 7:451-458, 2003b.

MARGESIN, R.; ZIMMERBAUER, A. \& SCHINNER, F. Soil lipase activity - a useful indicator of oil biodegradation. Biotechnol. Technol., 13:859-863, 1999.

MERKL，N.; SCHULTZE-KRAFT, R. \& INFANTE, C. Phytoremediation of petroleum-contaminated soils in the tropics - Pre-selection of the plant species from eastern Venezuela. J. Appl. Bot. Food Qual. - Angew. Bot., 78:184192, 2004.

MURATOVA, A.Y.; TURKOVSKAYA, O.V.; HÜBNER, T. \& KUSCHK, P. Studies of the efficacy of alfalfa and reed in the phytoremediation of hydrocarbon-polluted soil. Appl. Biochem. Microbiol., 39:599-605, 2003a

MURATOVA, A.Y.; HÜBNER, T.; NARULA, N.; WAND, H.; TURKOVSKAYA, O.; KUSCHK, P.; JAHN, R. \& MERBACH, W. Rhizosphere microflora of plants used for the phytoremediation of bitumen-contaminated soil. Microbiol. Res., 158:151-161, 2003b.

MUYZER, G.; DE WAAL, E.C. \& UITTERLINDEN, A. Profiling of complex microbial populations by denaturing gradient gel eletrophoresis analysis of polymerase chain reactionamplified genes coding for 16S rRNA. Appl. Environ. Microbiol., 59:695-700, 1993.

ØVREÅS, L.; FORNEY, L.; DAAE, F.L. \& TORSVIK, V. Distribution of bacterioplankton in meromictic Lake Saelenvannet, as determined by denaturing gradient gel electrophoresis of PCR-amplified gene fragments coding for 16S rRNA. Appl. Environ. Microbiol., 63:3367-3373, 1997.

PALMROTH, M.R.T.; MÜNSTER, U.; PICHTEL, J. \& PUHAKKA, J.A. Metabolic responses of microbiota to diesel fuel addition in vegetated soil. Biodegradation, 16:91-101, 2005.

PAULA, A.M.; SOARES, C.R.F.S. \& SIQUEIRA, J.O. Biomassa microbiana, atividade bioquímica e fungos micorrízicos arbusculares em solo de área de "landfarming" para tratamento de resíduos petroquímicos. R. Bras. Eng. Agríc. Amb., 10:448-455, 2006.

PEREIRA, J.C.; NEVES, M.C.P. \& DROZDOWICZ, A. Dinâmica das populações bacterianas em solos de cerrados. Pesq. Agropec. Bras., 34:801-811, 1999.

PHILLIPS, J.M. \& HAYMANN, D.S. Improved procedures for clearing roots and staining parasitic and vesiculararbuscular mycorrhizal fungi for rapid assessment of infection. Trans. British Mycol. Soc., 55:158-161, 1970. 
PIZZUL, L.; CASTILLO, M.P. \& STENSTRÖM, J. Characterization of selectec actinomycetes degrading polyaromatic hydrocarbons in liquid culture and spiked soil. World J. Microbiol. Biotechnol., 22:745-752, 2006.

PRADHAN, S.P.; CONRAD, J.R.; PATEREK, J.R. \& SRIVASTAVA, V.J. Potential of phytoremediation for treatment of PAHs in soil at MGP sites. J. Soil Contam., 7:467-480, 1998 .

RIFFALDI, R.; LEVI-MINZI, R.; CARDELLI, R.; PALUMBO, S. \& SAVIOZZI, A. Soil biological activities in monitoring the bioremediation of diesel oil-contaminated soil. Water Air Soil Pollut., 170:3-17, 2006.

ROBSON, D.B.; KNIGHT, J.D.; FARRELL, R.E. \& GERMIDA, J.J. Ability of cold-tolerant plants to grow in hydrocarboncontaminated soil. Int. J. Phytoremediat., 5:105-123, 2003.

SÁ, M.C.C. Tratamento biológico de solo contaminado com hidrocarbonetos de petróleo. Rio de Janeiro, Universidade Federal do Rio de Janeiro, 2002. 116p. (Tese de Mestrado)

SAMANTA, S.K; SINGH, O.V. \& JAIN, R.K. Polycyclic aromatic hydrocarbons: environmental pollution and bioremediation. Trends Biotechnol., 20:243-248, 2002.

SCHNÜRER, J. \& ROSSWALL, T. Fluorescein diacetate hydrolysis as a measure of total microbial activity in soil and litter. Appl. Environ. Microbiol., 43:1256-1261, 1982.
SICILIANO, S.D.; GERMIDA, J.J.; BANKS, K. \& GREER, C.W. Changes in microbial community composition and function during a polyaromatic hydrocarbon phytoremediation field trial. Appl. Environ. Microbiol., 69:483-489, 2003.

SIMS, R.C. \& SIMS, J.L. Landfarming of petroleum contaminated soils. In: ADRIANO, D.C.; BOLLAG, J.M.; FRANKBERGER JR., W.T. \& SIMS, R.C., eds. Bioremediation of contaminated soils. Madison, ASA/ CSSA/SSSA, 1999. p.767-781.

STAHL, P.D. \& WILLIAMS, S.E. Oil shale process water affects activity of vesicular-arbuscular fungi and Rhizobium 4 years after application to soil. Soil Biol. Biochem., 18:451$455,1986$.

SUSARLA, S.; MEDINA, V.F. \& MCCUTCHEON, S.C. Phytoremediation: An ecological solution to organic chemical contamination. Ecol. Eng., 18:647-658, 2002.

TRAPPE, J.M.; MOLINA, R. \& CASTELLANO, M. Reactions of mycorrhizal fungi and mycorrhiza formation to pesticides. Ann. Rev. Phytopathol., 22:331-359, 1984.

USEPA - United States Environmental Protection Agency. Disponível em: <http://www.epa.gov/SW-846/pdfs/ 8270d.pdf $>$. Acesso em 28 fev. 2008.

WELLINGTON, E.M.H. \& TOTH, I.K. Actinomycetes. In: WEAVER, R.W.; ANGLE, J.S. \& BOTTOMLEY, P.S., eds. Methods of soil analysis. Part 2. Microbiological and biochemical properties. Madison, Wisconsin, ASA/CSSA/ SSSA. 1994. p.199. 